Dossier Anthropology on Latin America and the Caribbean today:

New Theoretical and Methodological Challenges

\title{
Hacer antropología hoy desde América Latina: apuntes en torno a la reinvención de nuestras antropologías
}

\author{
Eduardo Restrepo' \\ 'Investigador independiente, Bogota, Colombia
}

\section{Resumen}

La creciente digitalización de nuestras experiencias y existencias, los procesos de derechización, y los entrampamientos burocráticos y precarización laboral son tres transformaciones que constituyen parte sustancial de las condiciones y retos en los distintos lugares de América Latina para la reinvención de nuestras antropologías. En este artículo se abordan estas transformaciones y se discuten sus implicaciones para la labor antropológica pensada desde América Latina.

Palabras clave: Transformaciones digitales, etnografía 2.o, procesos de derechización, entrampamientos burocráticos, antropologías universitarias, nuestras antropologías. 


\title{
Fazer antropologia atualmente na América Latina:
}

\section{Notas sobre a reinvenção de nossas antropologias}

\section{Resumo}

A digitalização crescente de nossas experiências e existências, os processos de direitismo, o aprisionamento burocrático e a precarização do trabalho são três transformações que constituem uma parte substancial das condições e desafios em diferentes partes da América Latina para a reinvenção de nossas antropologias. Este artigo aborda essas transformações e discute suas implicações para o pensamento do trabalho antropológico da América Latina.

Palavras-chave: Transformações digitais, etnografia 2.0, processos de direita, armadilhas burocráticas, antropologias universitárias, nossas antropologias.

\section{Currently doing anthropology in Latin America: Notes on the reinvention of our anthropologies}

\begin{abstract}
The increasing digitization of our experiences and existence, the processes of right-wingization, bureaucratic entrapment and job insecurity are three transformations that constitute a substantial part of the conditions and challenges in different parts of Latin America for the reinvention of our anthropologies. This article addresses these transformations and discusses their implications for anthropological work thought from Latin America. Keywords: Digital transformations, ethnography 2.0, right-wing processes, bureaucratic entrapments, university anthropologies, our anthropologies.
\end{abstract}




\title{
Hacer antropología hoy desde América Latina: apuntes en torno a la reinvención de nuestras antropologías
}

\author{
Eduardo Restrepo
}

\section{Introducción}

La pregunta por reinventar la antropología no es nueva. Suele instalarse en tiempos de crisis y rupturas. Con este título, por ejemplo, se publicó hace más de cincuenta años uno de los libros más relevantes de la tradición antropológica estadounidense. Editado por Dell Hymes (1974), Reinventing Anthropology, se compone de dieciséis capítulos escritos por distintos autores que abordan diferentes aspectos de un vital momento de la antropología estadounidense en aras de cuestionar parte importante de sus fundamentos y legados desde la pregunta política y ética del para qué de la antropología. Eran jóvenes antropólogos que, al calor de las luchas anticoloniales de liberación nacional, se preguntaban qué significaba hacer antropología desde un país de vocación neo-colonial como los Estados Unidos y las urgencias de transformarla.

Esta no fue la primera ni la última vez que los antropólogos se imaginan ante situaciones que los compelen a reinventarse, tampoco las rupturas suelen ser tan tajantes y parte de lo viejo se cuela incluso en las transformaciones más radicales. Las inercias disciplinares tienden a ser más pesadas de lo que los más entusiastas se alcanzan a imaginar. No obstante, parecen existir situaciones en las cuales parte de lo que hacemos como antropólogos y de lo que concebimos como antropología amerita reinventarse.

Entiendo "nuestras antropologías" como las antropologías que se hacen desde América Latina y que responden con relevancia política ante las realidades que nos interpelan y constituyen. Nuestras antropologías no son solo las antropologías que se hacen en América Latina, no son tampoco las que se hacen sobre América Latina. nuestras antropologías no son simplemente antropologías que se hacen en (o sobre) América Latina, sino que desde unas Américas Latinas asumidas como un horizonte ético-político articulado en las márgenes de una geopolítica del conocimiento y de un sistema mundo de la antropología. Nuestras antropologías implican un posicionamiento, antes que una posición de sujeto dada por una ubicación geográfica; suponen una articulación ético-política a partir de sus lugarizaciones. Es ese posicionamiento o articulación lo que define el locus de enunciación en nuestras antropologías. ${ }^{3}$

En este artículo quisiera examinar tres tipos de transformaciones que suponen que reinventemos de varias maneras nuestras antropologías: 1) las asociadas a la creciente digitalización de nuestras experiencias y existencias, 2) las vinculadas a los procesos de derechización, y 3) las referidas a los entrampamientos burocráticos y los procesos de precarización de la labor antropológica en los establecimientos universitarios.

\footnotetext{
1 Este texto es la elaboración a partir de mi presentación en el pasado Congreso de la Asociación Latinoamericana de Antropología. Agradezco a Lía Ferrero sus detallados y acertados comentarios al primer borrador del texto.

2 Esto de "lo nuestro", en la expresión de "nuestra América" es un concepto cuya genealogía se puede remontar al poeta y prócer de la independencia cubana José Martí, aunque en realidad es una noción-aspiración que ha circulado desde antes en el ideario de Simón Bolívar o, después, con el famoso contrapunteo entre Ariel y Calibán. Al igual que en Martí, mi apelación a lo nuestro es un posicionamiento crítico entorno a un proyecto político, antes que una esencialidad celebrada.

3 Esto no quiere decir que nuestras antropologías sean iguales, ni mucho menos que ese posicionamiento o articulación suponga una homogeneidad. Sabemos que hay periferias en la periferia, por supuesto. Las más visibles antropologías hechas en México y Brasil no son igualmente periferizadas a las de muchos otros países de América Latina. En un mismo país, incluso, las antropologías que se realizan en la capital y en las universidades con mayores recursos y prestigio suelen obliterar las antropologías que se hacen en las provincias o en universidades con condiciones de mayor precariedad.
} 
Obviamente, no son los únicos tipos de transformaciones que estamos enfrentando, aunque no son menores. Estos tres tipos de transformaciones no se encuentran aislados unos de otros. Aunque responden a distintas temporalidades y calados, se pueden trazar múltiples imbricaciones entre ellos.

Los dos primeros tipos de transformaciones que abordaré suponen nuevos encuadres teóricos y metodológicos en nuestras antropologías, retan nuestra imaginación disciplinaria de modos que difícilmente hubiéramos podido prever hace solo unas décadas. El tercero se refiere más inmediatamente a las condiciones materiales en las cuales desplegamos nuestras antropologías en los entornos universitarios, amenaza la viabilidad misma de la antropología como un proyecto intelectualmente relevante y la vitalidad irreverente de muchos antropólogos.

No quiero insinuar que tengamos que reinventar in toto las antropologías que hacemos desde América Latina, entre otras cosas porque el conocimiento antropológico de nuestras realidades y sus intervenciones son tan vastas que no se pueden reducir a las transformaciones y urgencias vividas. Estas transformaciones y urgencias tienen un lugar central, pero no se entienden como si aparecieran de la nada ni, mucho menos, subsumen toda nuestra existencia.

\section{Vidas digitalizadas}

El mundo que enfrentamos hoy en América Latina implica una creciente digitalización de nuestras experiencias y existencias que, con la pandemia del Covid-19, se ha hecho evidente en múltiples ámbitos de nuestra cotidianidad. Con la irrupción de la pandemia del Covid-19 nuestras vidas se han visto trastocadas, aunque de diferentes maneras y con distintos alcances dependiendo de marcaciones de generación, clase, raza y lugar. En cuestión de semanas, el mundo dejó de ser mucho de lo que dábamos por sentado. Una tras otra se fueron cerrando fronteras, se impusieron confinamientos obligados. La movilidad y las interacciones cara a cara se han reducido notablemente, cuando no totalmente interrumpido. No son pocas las corporalidades que se han acorazado, estableciendo distanciamientos y angustias que hace no mucho tiempo hubieran sido difíciles de imaginar.

Para una parte de la población, el Covid-19 ha implicado confinamientos, generalización de teletrabajo y una virtualidad obligatoria en la educación, entre otras súbitas transformaciones de la vida cotidiana. ${ }^{4}$ Esto ha supuesto, para muchos, largas horas sentados ante las pantallas de computadores $u$ otros dispositivos digitales realizando, en estos nuevos entornos, actividades que antes eran mayoritariamente presenciales. Para otros, tal vez los más, la pandemia ha traído hacinamiento y hambre, la repentina clausura de las actividades diarias con las que se ganaban la vida, violencia, violaciones y muerte.

Para el caso de la antropología, el Covid-19 interrumpió los ritmos y protocolos de la manera en que concebíamos el trabajo de campo en general y la etnografía en particular. El Covid-19, al clausurar abruptamente movilidades y comodidades del prefabricado libreto de la etnografía antropológica más convencional, instaura la ya inulible pregunta por cómo hacer hoy etnografía. Para muchos estas transformaciones han sido experimentadas como una angustiante parálisis traducida en la espera de que regresará el mundo como lo conocíamos antes, con los buenos viejos tiempos donde los antropólogos visitaban por largos periodos de tiempo a "sus" "comunidades", algunos incluso instalando "la tienda en el centro de la aldea" como lo demandaban los más puros preceptos malinowskianos.

4 Para gran parte de la gente, sin embargo, la que ha estado más precarizada, para esos que no merecen ser llorados (Butler), los condenados de la tierra (Fanon), sus ciclos educativos, si los tenían, fueron interrumpidos, con la pérdida de acceso a comedores escolares y comidas de las que muchos carecen en sus casas. 
Ahora bien, no podemos endosarle a la pandemia procesos de más largo aliento. Las cosas no pasaron de la noche a la mañana, ni muchas de ellas se disolverán una vez superada la pandemia del Covid-19. A empujones o como resultado de sutiles procesos, la digitalización de nuestras existencias y las experiencias vividas se ha profundizado y ampliado a una escala difícil de imaginar hace apenas algunos años. En cuestión de unas décadas, el mundo cambió sustancialmente, y por sus actitudes pareciera que algunos colegas no se han enterado. Para ellos las implicaciones para las vidas y subjetividades de los seres humanos con los que solemos estudiar se redujeran a nostálgicas querellas por unos imaginados tiempos en los que "sí se podía hacer campo de verdad", de una fantaseada comodidad epistemológica que hoy se les escapa.

Nuestras antropologías deben posibilitarnos entender qué está en juego hoy con las transformaciones digitales para la vida de las gentes con las que trabajamos, así como para las condiciones de existencia de todos en general. No es simplemente investigar con ayuda de estos nuevos artefactos y entornos, sino entender lo que estos vienen haciendo en nuestras vidas. Sus efectos en nuestras experiencias y existencias, no se reduce a tener acceso o no a los artefactos digitales (como el teléfono inteligente) y entornos digitales (como las plataformas trasmediáticas). Gústenos o no, la denominada "revolución digital" tiene efectos materiales concretos en la vida y la muerte de poblaciones, humanas y no humanas.

Con el denso entramado de las tecnologías digitales se ha profundizado la acumulación de capital, se han potenciado de disimiles maneras las articulaciones del mercado, y afinado los dispositivos de control y gobierno (Ribeiro, 2018). Nuestras sensibilidades e inteligibilidades se producen y cristalizan desde algoritmos que nos constituyen como mercancía, que definen burbujas de odio, afinan las capacidades de control y marcan nuestras subjetividades, tanto como posibilidades de accesos e interacciones (García Canclini, 2019).

Más puntualmente, la reinvención de nuestras antropologías hoy pasa por apropiarnos para la investigación etnográfica de las herramientas ofrecidas por los entornos y artefactos digitales, no solo para estudiar los emergentes escenarios virtuales sino también para potenciar el abordaje de temáticas, lugares y gentes que hace tiempo hemos abordado en sus fisicalidades 5 . Esto es todavía más pertinente si pensamos tanto en las etnografías de lo digital (de los mundos virtuales y sus interacciones con nuestras vidas), como la apropiación de lo digital para complementar las etnografías convencionales. Para recurrir a una metáfora derivada de la misma web, este doble movimiento implicaría lo que podríamos denominar una etnografía 2.o. ${ }^{6}$

Nacida en un contexto colonial, el modelo de etnografía antropológico convencional (que ha sido atravesada por una serie de supuestos sobre lugar, desplazamiento, otredad, exotismo y en una autoridad derivada de "colocar la tienda en el centro de la aldea de los nativos") se ha constituido en una traba de la imaginación y práctica etnográfica para asumir los alcances y retos de las grandes transformaciones asociadas a la creciente virtualización de nuestras experiencias y existencias. La etnografía 2.0 supone una ruptura con esas retóricas y nostalgias de un modelo idealizado de etnografía convencional antropológico, uno que podría ser llamado "complejo malinowskiano-geertziano".

Web 2.0 es el término acuñado para marcar el paso de los primeros sitios que alojaban contenidos para ser consultados por los internautas, a unos sitios en red que dejan de ser un simple recipiente de información para convertirse en escenarios de interacción, con diseños centrados en los usuarios y que hace énfasis en prácticas de colaboración e intercambio. En tal sentido, con etnografía 2.0 no busco indicar simplemente una

\footnotetext{
5 Utilizo el término de fisicalidad porque no podemos considerar que la virtualidad o lo digital no sean reales, no tengan grandes efectos en la realidad (con lo cual no se puede oponer virtualidad o digital a realidad), ni tampoco podemos plantear que la virtualidad o digitalidad no impliquen presencialidades, no movilicen articulaciones de presencialidad. Con el neologismo busco evitar esas equivocadas asociaciones de oponer presencialidad o realidad a virtualidad o lo digital.

6 No hay un consenso sobre cómo nombrar esta etnografía que aquí llamo etnografía 2.o. Diferentes autores han preferido referirse a etnografía digital, etnografía virtual y ciberetnografía (cfr. Estalella, 2018; Hine, 2004). Por su parte, netnografía es un término propuesto desde los estudios de mercado, y se enfoca más a las redes (del Fresno, 2011).
} 
etnografía que incluye como un tema más los artefactos y entornos digitales en el modelo etnográfico propio del complejo malinowskiano-geertziano.

Si queremos contribuir a entender, desde nuestras antropologías, lo que está en juego con estos artefactos y entornos digitales, así como sus múltiples y contradictorios efectos en nuestras experiencias y existencias, no podemos simplemente hacer unos cambios cosméticos a la etnografía (cfr. Gómez Cruz, 2018; Winocur, 2009).

Cuando hablo de etnografía 2.o estoy pensando en transformaciones que pasan por cómo hemos articulado la relación de la figura del etnógrafo, con quienes o lo que es etnografiado en un marco institucional muy particular que constituye el dispositivo etnográfico. Refiere a una serie de preguntas como ¿Qué significa en términos de las "políticas y poéticas de la representación etnográfica" (para usar una conocida expresión de los debates de los años ochenta) que no sea el etnógrafo quien controle los formatos y narrativas digitales, ni las redes ni los dispositivos por los que puede circular las representaciones que también lo implican? ¿Qué significa, por ejemplo, tomarse en serio que la relación entre etnógrafo y lo etnografiado puede establecerse en términos de lo colectivo y colaborativo (como ya se había avanzado en apuestas militantes o comprometidas de la etnografía) sino que la figura misma del etnógrafo sea implosionada desde los "consumidores" de la etnografía?

Un aspecto de particular relevancia derivado de estas transformaciones digitales para nuestras antropologías es asumir los cambios sobre las formas en las que usualmente aprendíamos y enseñábamos antropología (Reygadas, 2019). Al menos en Colombia, los pregrados (grados o licenciaturas en otros países), se encuentran bajo la mirada de las burocracias universitarias para hacerlos más rápidos, menos exigentes y, ojalá, en gran parte virtualizados. El socavamiento de los pregrados (y no solo de los de antropología), es un proceso que viene adelantándose desde los años noventa, en donde las dobles titulaciones, la reducción del número de semestres, la eliminación de la tesis (o el apocamiento de sus exigencias), ya había logrado alivianar y superficializar la formación antropológica en el nivel de pregrado. Sumado a esto el Covid-19 impuso la virtualización forzada, al menos en lo inmediato.

Parece que la reinvención de nuestras antropologías pasará también por tomarse en serio las transformaciones de la universidad en este plano de la virtualización, y no solo en lo que a la formación en pregrados se refiere. No parece probable que se transite a un modelo absolutamente virtual, pero todo parece indicar que no podemos postergar más la apropiación en serio de las potencialidades de la educación virtual a la formación antropológica. No considero que la educación virtual tiene que ser necesariamente de segunda o tercera categoría, no asumo que la presencialidad sea la única opción para todos los cursos en el proceso de formación de las nuevas generaciones de antropólogos. Probablemente, la virtualización de parte de los procesos de enseñanza y aprendizaje de la antropología apelará a los entornos virtuales.

No obstante, de las pocas cosas que están claras, es que la virtualización de la enseñanza de las nuevas generaciones no es simplemente tener encuentros sincrónicos de tres o más horas como se hacía en el salón de clases por alguna de las plataformas o aplicaciones a disposición, no se limita tampoco a subir a un repositorio o nube las lecturas que se les dejaban a los estudiantes en las papelerías para que las fotocopiaran. Entender la virtualización no como una maldición de la que desafortunadamente no podemos escapar, sino como una inusitada situación que nos permite transformar algunas inercias y tradiciones para asumir las potencialidades y especificidades de la educación virtual, es parte de la reinvención de nuestras antropologías.

\section{Procesos de derechización}

Hemos sido testigos de cómo, en nuestros países, se han ido posicionando una serie de procesos de derechización de los sentidos comunes, cotidianidades y de las estrategias políticas. Prácticas abiertamente racistas y xenofóbicas, que desprecian la existencia y derechos de poblaciones racializadas, minorizadas y 
migrantes, se han articulado en algunos países con la emergencia y elección de políticos de derecha que se vanaglorian de sus discursos y estrategias autoritarias e ignorancias. Veloz y atropelladamente, los gobiernos de derecha desmantelaron programas y mecanismos establecidos durante las pasadas décadas para socavar las desigualdades económicas y sociales. Los recientes gobiernos de corte más progresistas han intentado revertir los efectos más nefastos de estas políticas.

Los estallidos de revueltas populares, como en Chile, Bolivia y Colombia, que han aprovechado las clases políticas en el poder para desplegar los más brutales dispositivos policiales con un gran saldo de muertos, heridos, mutilados y desaparecidos, también han evidenciado las ansiedades de las nuevas derechas que se vienen rearticulando y transformando para responder por la fuerza, requiérase o no, para conservar el statu quo del que derivan sus privilegios.

Se hace cada vez más frecuente el escarnio público y asesinato a individuos o colectividades que ponen en riesgo el orden de privilegios y las maquinarias normalizantes. El cuerpo, el deseo y la cotidianidad son asaltados y desgarrados por la escrutadora mirada de la "gente de bien", por quienes se imaginan encarnado sujetos morales adecuados, empresarios de sí y bulímicos consumistas, que dicen despreciar las regulaciones y dadivas del estado, a menudo sujetos creyentes que se pliegan a las hordas de los justos. Tiempos en los que la opinión apresurada es equiparable a la cuidadosa investigación, en los que el encantamiento del mundo, los fakenews y la "post-verdad" campean como un cada vez más generalizado sentimiento de abierto antiintelectualismo (Ribeiro, 2017).

Este panorama constituye una serie de desafíos para nuestras antropologías. Nos colocan ante una disyuntiva que enfrentamos aquí y ahora los antropólogos entre evidenciar con resultados concretos unas antropologías relevantes social y políticamente ante los múltiples avances de estos procesos de derechización o caer en la banalización de nuestras antropologías para entender e interrumpir estos avances. Imaginar o enunciar que no se toma posición frente a esta encrucijada, es por supuesto asumir una posición. Nuestras antropologías no pueden esgrimir un cuestionado prurito cientista en aras de no involucrarse en las disputas que suponen estos tiempos sombríos.

Para escapar a la banalización de la antropología no es suficiente, sin embargo, con una abierta y "correcta" toma partido. No basta con estar del lado de "los buenos", no es suficiente con indignarse y movilizarse contra las fuerzas y prácticas de la derechización en particular u otras que apuntalen la desigualdad social en general. Para que nuestras antropologías sean relevantes deben hacer contribuciones concretas a conocer más adecuada y densamente los mundos que habitamos, a entender las fuerzas que los constituyen y que en gran parte imposibilitan que sean más justos, igualitarios y dignos para más gentes. Esto implica una ardua labor teórica y empírica, que no se agota en devenir comité de aplausos en narrativas hegemonizadas de lo políticamente correcto, en reposar cómodamente en lecturas homogenizantes, idealizadas y moralizantes que suelen circular a nombre de las más disimiles gentes sufrientes. Toca contribuir realmente a mover los umbrales de los imaginarios teóricos y de las disputas concretas que constituyen las subjetividades políticas, que perfilan el juego y los alcances de las agencias individuales y colectivas.

Una veta de su contribución estaría nuevamente en la etnografía (y no solo como etnografía 2.o). No es difícil encontrase con estudios o análisis sobre los procesos de derechización en nuestros países que se mueven en unos muy elevados niveles de abstracción que desconocen el denso y heterogéneo entramado de experiencias no vislumbradas, así como muchos otros efectos situados no contemplados en tales generalizaciones. Adelantar investigaciones etnográficamente orientadas arrojaría insumos concretos sobre las heterogéneas experiencias e implicaciones de eso que se engloba y asume como un "giro a la derecha" en los estudios y análisis más abstractos. 
Esto, por supuesto, nos permite comprender, desde la perspectiva de las gentes (en su relacionalidad, heterogeneidad y conflicto), con mayor adecuación qué es lo que realmente se encuentra en juego con lo que prefiero denominar procesos de derechización. No pretendo argumentar que estos niveles de abstracción sean irrelevantes. Tampoco busco argüir que en el juego de perspectivas situadas de las gentes se agota la explicación de un hecho social. Considero que eso no contemplado transforma lo que conocemos y, en últimas, lo que podemos hacer para interrumpir las emergencias y efectos de estos procesos de derechización.

Hacer etnografías "hacia arriba" y "hacia los lados", desnudar etnográficamente los sutiles mecanismos de la dominación que reproducen la desigualdad social se hace cada vez más vital para poder comprender cómo se configuran estos procesos de derechización. Para posibilitarlo, nuestras antropologías deben interrumpir el embrujo de centrarse en otrerizadas indianidades y romantizadas subalterninidades. El amarre del pecado original colonial de la antropología expresado en una imaginada antípoda de occidente o de la modernidad requiere ser desatado desde nuestras antropologías. Si queremos ser relevantes para las urgencias de nuestros tiempos y los avatares asociados a los procesos de derechización, debemos interrumpir el lastre de la nostalgia imperial que aun constituye parte importante de la imaginación antropológica.

\section{Entrampamientos burocráticos}

Las condiciones materiales de existencia de nuestras antropologías visiblemente han pasado por los establecimientos universitarios, donde se gestan los procesos de reproducción disciplinaria y la generación de lo que aparece como el conocimiento antropológico academizado (concretado en publicaciones, comunicaciones, congresos y demás). Este trabajo antropológico supone principalmente actividades de docencia y de investigación. No obstante, en nuestras antropologías, la gran parte de los trabajos como antropólogos se dan por fuera de estos establecimientos universitarios. Entender cómo se articula en concreto la economía política de nuestra disciplina y, en particular, las condiciones laborales y del ejercicio antropológico más allá de las universidades es indispensable para justipreciar y dimensionar nuestras antropologías realmente existentes. Como lo ha subrayado Gonzalo Díaz Crovetto (2018), entender la antropología no puede dejar de lado abordarla como un trabajo, es decir, en sus condiciones materiales de reproducción de la existencia en tanto antropólogos.

Para este breve artículo quiero indicar algunas transformaciones de lo que significa ganarse la vida como antropólogo que ha sido contratado por una universidad. Casi todo lo que voy a decir no aplica solo a los antropólogos, por supuesto; pero encorseta poderosamente lo que podemos hacer desde la antropología universitaria. Debo partir de señalar que no todos los antropólogos son contratados en las universidades para ser docentes, aunque esto es lo más frecuente. Además, no todos antropólogos contratados como docentes cuentan con las mismas condiciones laborales. En Colombia, por ejemplo, hay dos grandes tipos de contratación de un docente en una universidad, sea esta universidad pública o privada. Los profesores de planta con un contrato laboral de tiempo completo o medio tiempo, y los profesores de cátedra con contratos de servicio para dictar uno o varios cursos, que se les pagan por horas.

Sobre todo los profesores de cátedra son cada vez más precarizados. No se puede sobrevivir como profesor de cátedra, a menos que se dicten varios cursos a la vez y, a menudo, en diferentes universidades al tiempo. Como si esto fuera poco, sus contratos de servicio los ponen en una permanente situación de incertidumbre sobre si van a ser contratados o no para el siguiente semestre. Más todavía, si se tiene en cuenta la existencia de un nutrido y ansioso "ejército de docentes de reserva", en el cual la burocracia académica puede fácilmente encontrar quien dicte cualquier clase cualesquiera sean las condiciones. Así, los profesores de cátedra son piezas que pueden ser fácilmente reemplazables. Esto los tiende a hacer sujetos dóciles de los cuales se puede prescindir. Son fuerza de trabajo dispensable. 
Los profesores de planta, por su parte, cargan el creciente peso de una burocracia universitaria cada vez más envalentonada por modelos gerenciales que han cooptado a las universidades, públicas y privadas. Con el incremento de la burocracia universitaria, se han ido transformado las prácticas docentes, investigativas y de extensión que habían definido a las universidades hasta los años noventa (Krotz, 2011; Graeber, 2015). Un fuerte entramado de regulaciones y demandas burocráticas han irrumpido en la vida de los docentes, sobre todo si están al frente de la dirección de un departamento o programa. Estos procedimientos, que estandarizan y regulan tiempos y prácticas, son diseñados en nombre de grandes palabras como "calidad", “eficacia”, "productividad" y "transparencia" (Restrepo, 2019). Suponen, en la práctica, el posicionamiento de un modelo gerencial que transforma a la universidad en una empresa en la cual un ejército de burócratas ha adquirido el papel central y las oficinas de mercadeo, con sus lenguajes y lógicas, son omnipresentes. Bien lo ha indicado David Greaber al plantear que en esta era de la "burocratización total" de nuestras existencias "La burocracia se ha convertido en el agua en que nadamos" (2015: 8).

Podemos llamar entrampamientos burocráticos a la urdimbre de minuciosos procedimientos que orientan cada vez más el tiempo y la energía de los docentes a producir los indicadores legibles y cuantificables por un modelo gerencial de universidad. 7 Teniendo como punta de lanza a los (a veces desdichados) encargados de dirigir los departamentos y programas, el cuerpo de docentes contratado para enseñar es evaluado por una espesa urdimbre de indicadores en los cuales el peso de otros productos (como la publicación en revistas indexadas) es tanto o mayor que el de su desempeño docente (Díaz Crovetto, 2018; Mejías, 2018).

Desde la perspectiva de las demandantes burocracias universitarias, no importa tanto cómo formemos a las nuevas generaciones de antropólogos, si lo hacemos de tal manera que garanticemos la demanda del mercado de formación antropológica y que salga lo más rápido y barato posible para la universidad. En últimas no importa, incluso, que tan buenos o malos docentes seamos, ni siquiera que tan relevantes investigaciones hagamos, con tal de que les cumplamos con las cuotas de las publicaciones y de ganancias que embrujan la imaginación burocrática (Godoy, 2017).

Estos entrampamientos burocráticos han hecho de la universidad algo muy distinto de un lugar donde primen asuntos como la producción de conocimiento, la pasión por los procesos de enseñanza y aprendizaje y la articulación de escenarios reflexivos y deliberativos de cara a las urgencias y sensibilidades de nuestras sociedades. Los entrampamientos burocráticos han esterilizado el alma de la vida universitaria.

Para nuestras antropologías estos entrampamientos y transformación de las universidades ha tenido efectos nefastos. No pocos colegas se han plegado, a regañadientes en su gran mayoría, a las demandas de la burocracia académica orientadas hacia la generación de indicadores de productividad. Recorren congresos, escriben artículos para presentar a revistas indexadas y adelantan investigaciones financiadas en consultorías ansiosos de recibir certificados y cumplir con las demandas de estas ansiosas burocracias. Esto ha disparado el volumen de textos, eventos y estudios antropológicos, pero la ligereza y la premura en muchos de ellos es lo que prima (Lomnitz, 2016). ${ }^{8}$

\footnotetext{
7 No son pocas las horas de la jornada laboral dedicadas a reuniones y a responder correos electrónicos con diversas solicitudes y tareas asignadas desde las distintas instancias de una demandante burocracia universitaria. Todas estas oficinas, divisiones y centros se muestran urgidos de introducir nuevos procedimientos, se muestran particularmente creativos para inventarse cada vez más formatos que llenar. Con frecuencia, convocan a reuniones o talleres obligatorios en los que ofrecen capacitaciones para que los directores de programa o profesores puedan responder adecuadamente y a tiempo a sus nuevas demandas.

8 Lía Ferrero, en un comentario en este punto, escribía sobre el riesgo en caer idealizaciones con respecto a un "pasado dorado, en el que el investigador, mayormente varón, tenían el tiempo necesario para producir investigaciones serias. Y esos espacios eran espacios absolutamente exclusivos, cerrados, pequeños". Esta observación es de gran pertinencia, ya que el cuestionamiento a los ritmos y condiciones en las que opera gran parte de la investigación antropológica hoy en América Latina, no puede significar una burda deificación de cómo se hacía antes.
} 
La investigación antropológica desde las universidades se ha convertido en una actividad fuertemente regulada y estructurada por demandas de las burocracias universitarias. Tristemente no son pocos los colegas febrilmente ocupados en alimentar sus curriculum vitae a como dé lugar, angustiados con satisfacer los caprichos de las autoridades burocráticas de turno para no perder sus (a menudo precarios) trabajos. Muchos aparecen engolosinados con las temáticas y autores más visibles y reconocidos en los establecimientos estadounidenses o europeos dominantes, engrosando producciones plegadas y miméticas que son en gran parte descontextuadas e irrelevantes para nuestras realidades y urgencias.

Podríamos decir, incluso, que estas transformaciones suponen también una derechización, una sutil y desde adentro, al clausurar el horizonte de politicidad crítica y disruptiva para articularse dócilmente a los imperativos de un modelo gerencial de universidad plegado a los intereses del mercado. Por eso, los ritmos, prioridades, alcances y estilos de unas antropologías relevantes para entender y hacer desde nuestras realidades encuentran cada vez menos lugar en los entornos universitarios.

\section{Conclusiones}

La antropóloga colombiana Myriam Jimeno (2000) acuñó en los años noventa el concepto de investigador ciudadano para señalar cómo los antropólogos en América Latina usualmente estudiábamos nuestras propias sociedades en aras de contribuir políticamente, desde nuestra disciplina, a superar las problemáticas de la desigualdad, racismo y discriminación de nuestras propias realidades. Este concepto de Jimeno nos recuerda que hacemos antropología no para contribuir acumular conocimiento disciplinario en abstracto, sino para encarar los avatares de nuestras propias existencias.

No son pocas, ni menores, las problemáticas que enfrentamos desde América Latina. Algunas se remontan atrás en los tiempos, otras son emergencias asociadas a más recientes transformaciones. En este artículo he abordado solo tres, dejando de lado muchas otras. Frente a la creciente digitalización de nuestras existencias y experiencias, nuestras antropologías no pueden quedarse en nostalgias sobre los "buenos viejos tiempos". Tenemos que contribuir a entender los múltiples efectos del posicionamiento en nuestras vidas de los artefactos y entornos digitales. No sirve de mucho aferrarse a inercias y patrioterismos disciplinarios que fetichizan modelos idealizados e inexistentes de etnografía, con el único resultado de clausurar lo que nos asusta e ignoramos. Gústenos o no, cualquier etnografía hoy supone hacer etnografía digital. Como lo ha planteado Edgar Cruz, ${ }^{9}$ antes que hablar de una etnografía digital en contraste con una que no lo es, debemos entender que lo digital ha transformado no solo nuestras vidas sino nuestras maneras de hacer etnografía.

Para enfrentar los intrincados amarres de los procesos de derechización articulados en nuestras formaciones sociales, nuestras antropologías deben alterar la inercia conceptual y política de sus ensimismamientos heredados de las nostalgias imperiales por subalternas puridades usualmente cristalizadas en indianidades o negridades como otreridades radicales. Los pegajosos lenguajes de los giros ontológicos o de las clausuras abya-yalistas suelen operan más como auto-orientalismos que como catalizadores teórico-metodológicos para interrumpir dichas nostalgias. Urgen etnografías hacia arriba y hacia los lados, que desnuden las tecnologías de la subalternización y la exclusión, que interrumpan los sentidos comunes clasemedieros y de las clases económicas, mediáticas y políticas dominantes.

9 Conferencia inaugural Edgar Gómez Cruz en la Escuela Doctoral de Primavera (Jerez de la Frontera, 12 de marzo de 2020): "El futuro de la comunicación en la cultura algorítmica: investigación e intervención”. https://www.youtube.com/watch?v=1KqWUgp_Ct4 
Finalmente, debido a los entrampamientos burocráticos y los procesos de precarización que indicamos, la universidad es cada vez menos el escenario para potenciar unas antropologías relevantes. Mientras los colegas anden mendigando certificados, abrumados en océanos de formatos por llenar, atareados para bulímicamente publicar en revistas indexadas, para mantener sus (a menudo precarios) empleos, poco o nada se puede realmente esperar de la antropología universitaria. Seguro firmarán febrilmente comunicados en las redes y en los congresos, probablemente se quejarán de las burocracias, hasta tal vez enfermen de estrés. Por eso, la relevancia de nuestras antropologías pasa hoy, como nunca, por articular otros escenarios donde la práctica antropológica (más allá de los papers y certificados) pueda florecer.

Recibido: 21 de julio de 2021

Acepto: 23 de agosto de 2021

\section{Referencias citadas}

DEL FRESNO, Miguel. 2011. Netnografía Investigación, análisis e intervención social online. Barcelona: Universitat Oberta de Catalunya.

DÍAZ CROVETTO, Gonzalo. 2018. "El valor de las palabras: control, disciplinamiento y poder en torno al conocimiento antropológico: lecturas y reflexiones a partir del caso chileno". En: Pablo Gatti y Lydia de Souza (eds.), Diálogos con la antropología latinoamericana. Montevideo: ALA. pp. 13-22.

ESTALELLA, Adolfo. 2018. "Etnografías de lo digital: Remediaciones y recursividad del método antropológico". AIBR: Revista de Antropología Iberoamericana, 13(1): 45-68.

GARCÍA CANCLINI, Néstor. 2019. Ciudadanos reemplazados por algoritmos. Guadalajara: Calas.

GRAEBER, David. 2015. La utopía de las normas: de la tecnología, la estupidez y los secretos placeres de la burocracia. Barcelona: Editorial Planeta.

GODOY, Mónica. 2017. "Que no cuenten con nuestra astucia”: lógicas neoliberales en la antropología colombiana. Universitas Humanística, 84: 309-325.

GÓMEZ CRUZ, Edgar. 2018. "Etnografía celular: una propuesta emergente de etnografía digital". Virtualis. Revista de Cultura Digital, 8(16): 77-98.

HINE, Christine. 2004. Etnografía virtual. Barcelona: Editorial UOC.

HYMES, Dell. 1974 [1969] (ed.). Reinventing Anthropology. New York: Vintage Books.

JIMENO, Myriam. 2000. "La emergencia del investigador ciudadano: estilos de antropología y crisis de modelos en la antropología colombiana”. En: Jairo Tocancipá (ed.), La formación del Estado Nación y las disciplinas sociales en Colombia. Popayán: Taller Editorial, Universidad del Cauca. pp.157-19o.

KROTZ, Esteban. 2011. "Las ciencias sociales frente al 'Triángulo de las Bermudas': una hipótesis sobre las transformaciones recientes de la investigación científica y la educación superior en México". Revista de El Colegio de San Luis, Nueva época, 1: 19-46.

LOMNITZ, Claudio. 2016. “Curriculismo mágico”. La Jornada, México. https:/www.jornada.com.

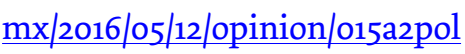

MEJÍAS, Annel. 2018. ¿Cómo visibilizar la ciencia en el Sur? Crítica al sistema de indexación vigente. Plural. Revista de la Asociación Latinoamericana de Antropología, 1(1): 187-202. 
RESTREPO, Eduardo. 2019. "Investigación en ciencias sociales desde los posgrados en Colombia”. Nómadas, 50: 45-59.

REYGADAS, Luis. 2019. Antropolog@s del milenio: desigualdad, precarización y heterogeneidad en las condiciones laborales de la antropología en México. México: CIESAS.

RIBEIRO, Gustavo Lins. 2017. "Giro global a la derecha y la relevancia de la antropología”. Encartes antropológicos, 1: 5-26.

RIBEIRO, Gustavo Lins. 2018. Otras globalizaciones. México: Gedisa.

WINOCUR, Rosalía. 2009. Robinson Crusoe ya tiene celular. México: Editorial Siglo XXI.

\section{Eduardo Restrepo}

https://orcid.org/0000-0002-5634-465X

E-mail: eduardoa.restrepo@gmail.com 